\title{
Perception of online feedback and its impact on cognitive and emotional engagement with feedback
}

\author{
Rosa M. Mayordomo ${ }^{1}$ (D) . Anna Espasa ${ }^{1} \cdot$ Teresa Guasch $^{1}$. \\ Montserrat Martínez-Melo ${ }^{1}$
}

Received: 9 November 2021 / Accepted: 9 February 2022 / Published online: 26 February 2022

(c) The Author(s) 2022

\begin{abstract}
Online feedback plays a key role in learning, but this requires that students engage with feedback. Some authors identify students' perception of feedback as relevant to understanding engagement. To measure the effect that perceived feedback (specifically its valence) has upon engagement with feedback, a quasi-experimental study has been carried out between two groups of master's students (191 students, 91.6\% women, with a mean age of 30.6 years): a group in which students had the possibility to resubmit an assignment after feedback and another group in which students only received feedback at the end of the assignment. Results show there are no significant differences between both groups regarding the perception of the feedback. However, the results point to the importance of feedback valence perception in resubmission situation. In this situation, a significant relationship between emotional engagement and cognitive engagement with feedback was identified depending on how the feedback was perceived. The main conclusions are the need of incorporating opportunities for resubmission to promote engagement with feedback, the relevance of the perception of feedback, and the role of emotional engagement plays in relation to cognitive engagement with feedback.
\end{abstract}

Keywords Feedback perception · Feedback engagement - Emotional engagement . Cognitive engagement $\cdot$ Online education

\section{Introduction}

Numerous studies point to the importance of feedback in learning (Hattie \& Timperley, 2007; Evans, 2013; Winstone et al., 2017) and the need for students to understand feedback and make decisions based on it. Carless (2015) defines feedback

Rosa M. Mayordomo

mmayordomo@uoc.edu

https://orcid.org/0000-0001-6149-2764

Extended author information available on the last page of the article 
as a dialog process in which students attribute a sense to information and use it to improve the quality of their work or learning strategies. According to this definition, for feedback to fulfil its role, students must be engaged in understanding and using it (Winstone et al., 2017). If feedback is not used, it is not considered effective (Boud \& Molloy, 2013). Different studies have pointed to different strategies to promote student engagement with feedback (Winstone et al., 2017). Among these strategies is the possibility of providing opportunities for resubmission, allowing students to make possible changes and improvements during the execution of the assignment based on the feedback received.

However, even when implementing this strategy, students are not guaranteed to engage with the feedback (Ali et al., 2018; Zhang \& Hylang, 2022). According to Zhang and Hyland (2022), teachers have a fundamental role in promoting student engagement with feedback, stating the fact that teachers heavily influence students' perceptions of feedback. Van der Kleij and Lippevich (2020), discuss the importance of how students perceive feedback in relation to how they engage with it. However, few studies have focused on providing empirical evidence on how this perception influences engagement with feedback (Wu \& Schun, 2020). The objective of this study is to analyse the role of students' perception of feedback regarding their overall engagement with feedback. To explore this objective, we will analyze the relationships between students' perception of online feedback and their engagement with it under two different conditions: when feedback is provided on a draft and students have the possibility to resubmit their work, and when students only receive feedback once they have already delivered the final assignment.

\subsection{Engagement with feedback}

Research on student engagement with feedback in higher education has been constant in recent years. Price et al. (2011) point out that engagement with feedback should be supported to reinforce that process. It is the students' engagement with the feedback rather than the feedback itself that is crucial for learning (Zhang \& Hyland, 2022). The review of Winstone et al. (2017) is particularly relevant because from a theoretical point of view, it proposes different strategies to promote engagement with feedback. Among these strategies, the resubmission of an academic task is proposed, meaning that students are provided feedback on a draft and given the opportunity to redo the task and hand it in again. When students only receive feedback at the end of the assignment, they do not see the value of being able to apply it (Yorke, 2003; Ali et al., 2018). In recent years, research on engagement with feedback in the context of resubmission situations has proliferated. Fisher et al. (2011) have analysed this strategy and its impact on learning. The results obtained in this study confirmed that the group receiving the intervention (reprocessing strategy) had better results than the control group. The number of studies in virtual or technology-supported environments has also increased (Hepplestone et al., 2011; Parkin et al., 2012).

Zhang and Hyland (2018) conducted a study analyzing how two L2 college students engaged with the feedback from their teacher compared to the feedback provided by automated writing evaluation (AWE) about their writing throughout a 
semester. These authors proposed a model to examine students' engagement with feedback in L2 writing. Based on the characterization of engagement of Fredricks et al. (2004), they suggested a model of feedback engagement that included three dimensions: behavioural, affective, and cognitive. The results indicated that the more engaged students spent more time working on the feedback, showed more positive attitudes towards it, and used more revision strategies. Yu et al. (2019) conducted a study in which they analyzed how three master's students engaged with peer feedback on drafts of their thesis, examining the affective, behavioral, and cognitive dimensions of their engagement. The results showed that the three dimensions of engagement were interrelated in a dynamic and complex way. Although they found distinctions within student engagement, they identified that affective engagement could promote or negatively influence behavioral and cognitive engagement. Shi (2021) examined six second-year English students and how they engaged behaviorally, cognitively, and affectively with automated, peer, and teacher feedback in three genres (argumentation, exposition, and narration) in an online L2 writing class throughout one semester. The author identified diversity as a significant factor when it comes to student engagement. According to the author, this demonstrates the complexity of the engagement process and the mediating effect of contextual and individual factors on engagement. The study by Zhang and Hyland (2022) explored how 33 college students engage with different types of L2 writing feedback (feedback through AWE, through peers, and from the teacher) and how the integration of these types of feedback could influence student engagement. The study concluded that integrating the three types of feedback in the preparation stage of the assignment played a fundamental role in facilitating student engagement with the feedback. Regarding the behavioral and affective dimensions, the students not only needed to spend time and effort in revising after receiving the feedback, but they also had to regulate emotional reactions to the feedback. This study reinforces the belief that feedback engagement is a complex process.

Like Zhang and Hyland (2022), in this study we start from a view of engagement as a multidimensional construct of at least three interrelated dimensions: behavioral, cognitive, emotional, (Fredricks et al., 2004; Zhang \& Hyland, 2018). We consider that behavioral engagement with feedback in online environments refers to the actions or behaviors that students have in relation to feedback. This spans from their reading it once received to actions of asking their teacher and peers questions in relation to the feedback to later use of said information. We assume the fact that behavioural engagement with feedback is necessary, but not sufficient, for the feedback to fulfil its function. In other words, they can engage with feedback behaviourally but not cognitively. To characterize cognitive engagement with feedback, we use one of the approaches of Fredricks et al. (2004) that defines cognitive engagement in terms of being strategic or self-regulated. In this context, cognitive engagement with feedback is understood as the use of external regulation (in this case feedback) to control the degree of understanding of the assignment and to plan, monitor and evaluate their cognition in relation to the introduction of improvements to the performance of the assignment. We understand emotional engagement with feedback as the students' affective reactions to it. For its characterization, we start from the control-value theory of achievement emotions (Pekrun, 2006). In this theory, 
Perkrun (2006), considers feedback one of the contextual factors that influence students' emotions. Within the different types of emotions studied, we will focus on achievement emotions, considering (as the authors do) two dimensions to characterize emotions: valence and arousal activation. Using these two dimensions, Perkrun et al. (2011) distinguish four categories of emotional response: positive activating emotions; positive deactivating emotions; negative activating emotions; and negative deactivating emotions.

\subsection{Perception of feedback, feedback valence (positive and negative) and its relationship with feedback engagement}

The studies presented thus far have highlighted the complexity and multidimensionality of engaging with feedback and the relationship of emotional engagement with behavioural and cognitive engagement. Likewise, they underscore the relevance of investigating the factors that can influence the variability of students' engagement with feedback, considering that there are instances where students don't engage with feedback, even in potentially useful situations, such as when re-submitting an assignment. Providing feedback can call attention to shortcomings in student performance, which may lead to positive or negative consequences in terms of student engagement. As Carless and Boud (2018) state, one obstacle that teachers face is providing motivating and instructive feedback given the different reactions it may cause among students. For feedback to have the potential to influence student learning, the active role of the student in processing feedback is necessary. Students must perceive it, understand it, consider it useful for their learning, have the opportunity to use it, be motivated to do it and ultimately use it (Havnes et al., 2012; Gamlem \& Smith, 2013). The emphasis on the student's mental and thought processes when receiving feedback emphasizes the importance of the role of feedback perception as a mediating factor in its processing (Strijbos et al., 2021). Understanding how students perceive feedback is fundamental to understanding engagement with feedback (Van der Kleij, 2019).In recent years, the study of students' perception of feedback has proliferated. In an exhaustive review, Van der Kleij and Lippevich (2020) point out that studies on feedback perception have focused on different aspects. Thus, studies have been carried out on perception of the characteristics of the feedback, its quality, its usefulness, the channel through which the feedback is provided, the source of the feedback, the quantity of feedback, its specificity, and its valence (positive and negative), the characteristics of the students that influence this perception, as well as the different perceptions between students and teacher. In his study Van der Kleij and Lippevich (2020) point out that several studies demonstrate that positive and negative emotions relate to how feedback is perceived and that the perception of it is influenced by the possibility of using it. They also refer to studies that link positive feedback perceptions to learning improvements and negative feedback perceptions to a lack of learning, both of which were reported by students. As Zhao et al. (2021) point out, evaluation and feedback processes place a significant emotional burden onto students. Research has shown that both positive and negative feedback, cause emotions that have the potential to support or interfere with 
learning (Hargreaves, 2013; Hattie \& Timperley, 2007). When students experience adverse emotional reactions because of the feedback process, their responsiveness may be limited (Carless, 2006). According to Ryan and Henderson (2018), research indicates that students are more likely to reject or ignore feedback if it evokes negative emotional responses. According to Gibbs and Simpson (2004), critical feedback cause negative emotional reactions.

Fong et al. (2016) conducted a survey study in which they asked students to provide information about their emotions in different imaginary feedback situations. In this study, they tried to understand the emotions associated with constructive critical feedback, distinguishing it from negative or positive feedback through identifying their emotions related to receiving feedback. The results showed that hope was experienced differently when imagining constructive feedback than when imagining positive and/or negative feedback. Hope was associated as a standalone emotion linked to constructive feedback and combined with other emotions in the case of positive and negative feedback. According to the authors, while positive feedback may suggest the likelihood of future success, feedback based on constructive criticism directly provides students with specific behaviours they can use to improve the assignment, thus giving them a sense of control over future results.

In general, the results of the studies point to the influence of feedback and its valence in terms of the emotions and subsequent learning of the students, although sometimes the results regarding the sense of influence are inconclusive. We share with Jarrell et al. (2017), the consideration that the valence of the feedback students receive will be based not on the characteristics of the message itself, but on the students' interpretation of feedback messages. Fong et al. (2018) indicate that the research has not taken into consideration much the students' view of how feedback affects them and the conditions that would have to be established for feedback to be more useful and effective. Moreover, Kim and Lee (2019) mention that because feedback can cause positive and negative emotions, it becomes increasingly necessary to adjust feedback to this emotional response since the affective process through which students interpret feedback is also an important element to be considered when explaining students' behaviour and self-regulation processes.

As we have mentioned, a large portion of these studies have been carried out in the context of L2 writing tasks, in situations in which revision is possible and in which there is an integration of different types of feedback. These studies are either case studies or studies using small samples. As these studies show, engagement is a complex process and not all students are engaged or are engaged in the same way with feedback, despite having opportunities to resubmit and, therefore, to use the feedback received. In this sense, we know little about what kind of factors could mediate such engagement in these resubmission processes (Zhang \& Hyland, 2022). Likewise, we have indicated the importance of the perception of feedback by students and its valence in the engagement with it. Currently, many of the studies on feedback perception focus on the understanding of feedback, agreement with feedback, and its usefulness. These are studies that tend to focus on student preferences in relation to feedback, but not on identifying the effects of feedback characteristics on students' perception of feedback and their subsequent engagement (Wu \& Schun, 2020). In this context, it is necessary to ask if the complexity and interrelation 
identified between engagement and feedback occurs in other activities/tasks around other subjects/content in which opportunities for resubmission are also provided, and if the perception of the valence of the feedback, at the moment of receiving the feedback, influences the variability of the students' engagement with the feedback in instances of resubmission.

\subsection{The purpose of the current study}

The overall objective of this study is to examine the role of perceived feedback valence in engagement with feedback in resubmission situations. That is, in situations designed with the aim that students can perceive the usefulness of engaging with feedback in contrast to other situations in which the later usefulness of engaging with feedback may be less evident and/or explicit. This general objective is specified in the following specific research questions.

\subsection{Research questions}

1. Are there differences in the perception of the feedback received once the assignment is complete depending on whether the students have previously prepared a draft and have received feedback in relation to it or if they have not?

2. Is there a relationship between the perceived valence of feedback received and emotional engagement with feedback? Does this relationship vary depending on whether or not students can resubmit the assignment after receiving feedback?

3. Is there a relationship between the perceived valence of feedback received and cognitive engagement with feedback? Does this relationship vary depending on whether or not students can resubmit the assignment after receiving feedback?

4. Does the students' perceived valence of feedback relate to how emotional engagement interrelates or mediates cognitive engagement with feedback?

\section{Materials and methods}

\subsection{Methodology}

A quasi-experiment (see Fig. 1) was carried out within an online environment with the aim of studying the impact of the perceived valence of feedback received by students on their engagement with feedback. Students were randomly assigned to each class-group and to a specific experimental situation: students who receive feedback on a draft during and at the end of the assignment (quasi-experimental group) and students who receive feedback exclusively at the end of the assignment (control group). The random allocation of class groups to experimental conditions sought to respect their natural ecosystem. In turn, other experimental conditions were controlled: All students were of the same level and course; class groups worked in the same way with teachers coordinated with the same methodology, which evaluates and gives feedback using the same procedure. In relation to feedback, the lecturers 


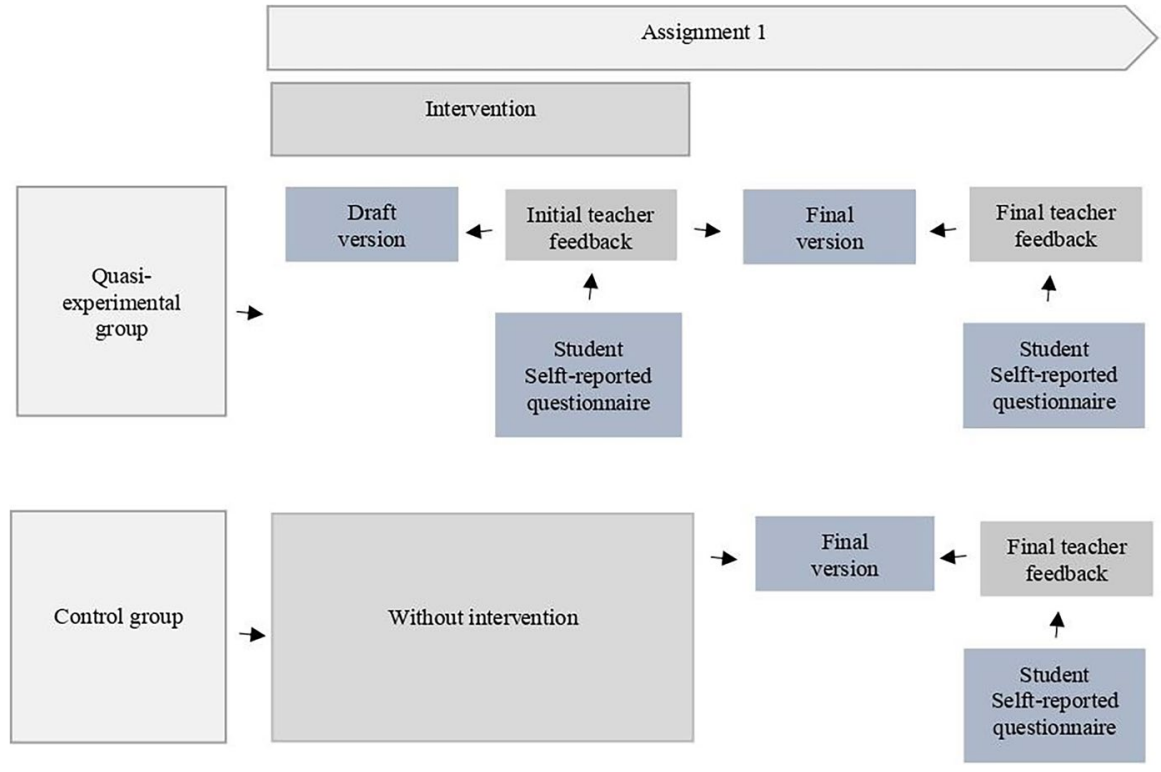

Fig. 1 Quasi-experiment procedure

were trained to provide the same type of feedback (feedback that promotes learning, based on providing guidance for improvement, i.e., constructive critical feedback according to Fong et al. (2016) or epistemic and suggestive feedback according to Guasch et al., 2013).

This article focuses on the results of the emotional and cognitive engagement of students in receiving feedback on drafts during the first assignment, as well as at the end of the first assignment, allowing comparison of the quasi-experimental group (who receive feedback on a draft -initial feedback- and receive feedback at the end of the assignment - final feedback) with the control group (who receive feedback only after delivering the final version of the assignment - final feedback). In turn, the results have been analysed by evaluating the perceived valence of the feedback that students have at each moment of the learning and evaluation processes.

\subsection{Context and sample}

The research was carried out at the Open University of Catalonia (UOC). This is an online university offering undergraduate and graduate training. Because of its history and size, the UOC can be considered a representative case of a large online university.

The study presented is part of a broader investigation that aims to identify different factors that affect students' engagement with online feedback and its evolution in the context of an argumentative essay. In order to identify as many factors as possible, we selected a sample of students who, theoretically, could have a high interest in 
the subject in which the data is collected, and therefore perhaps show a high level of engagement. A sample of students in a master's program within a professional major was selected, with the implication of professional development, where the majority of students are in-service teachers. In the context of this master's degree, the sample is made up of students taking an elective course, following the same criteria for the students' interest in the subject and their greater engagement. Specifically, the research was conducted with students taking the course 'Reading Learning Disorders' within the Master's Degree in Learning Difficulties and Language Disorders.

Informed consent for the research was obtained from the teaching staff and students. Likewise, the project in which this study is framed was approved by the Ethics Committee of the Open University of Catalonia.

A total of 191 students completed the intermediate (in the case of the quasiexperimental group) and final (quasi-experimental group and control group) questionnaires. As indicated, this article analyzes the specific results of the students in the groups that had the opportunity to revise their work based on the feedback received (111) compared to the control group (80). The sample was made up of 91.6\% women, and students with a mean age of 30.6 years (MD: 30 and SD=0.28).

Although it is not customary to identify sample validity and precision in quasiexperimental designs in pre-established groups (such as classrooms or class groups) (Fernández-Garcia et al., 2014), it is important to report these criteria to assess the power of the results obtained from different criteria, and specifically the external validity. On the one hand, if the entire classroom group initially enrolled in the subject is considered as the universe of study and was randomly assigned to the experimental situations $(\mathrm{N}=254)$, the total sample obtained $(\mathrm{n}=191)$ implies a margin of error global results of +3.65 , for a confidence level of $95 \%$ (under the assumptions of random sampling in finite universes and $p=q=50$ ). On the other hand, it is a quasi-experiment that limits the bias in the errors, given that the samples are balanced, and various ex-ante measures did not present significant differences between groups.

\subsection{Data collection instrument}

The measurement of the indicators of the variables were reported by the students through questionnaires administered online. The design of the questionnaire was based on the bibliographic review reported in the introductory section. The different variables were operated based on indicators validated in existing questionnaires that were adapted to the context (online) and specific theme (feedback).

Regarding questions for cognitive engagement information, the characterization of cognitive engagement by Fredricks et al. (2004) and Fredricks et al. (2016) was taken as a reference. Based on the conceptualization of these authors, the indicators were adapted to the situation of this study (online context) with a specific focus on engagement with feedback. The following Table 1 shows cognitive engagement indicators:

Regarding emotional engagement with the feedback, The Achievement Emotions Questionnaire (AEQ), (Pekrun et al., 2011) was used adapting some indicators to the 
Table 1 Cognitive engagement indicators in online environment

\begin{tabular}{|c|c|}
\hline Engagement type & Indicator \\
\hline Not use of feedback & $\begin{array}{l}\text { I don't tend to do anything with the feedback received } \\
\text { even if I have to resubmit my work }\end{array}$ \\
\hline \multirow[t]{2}{*}{ Reading } & I always read the feedback I receive \\
\hline & I comment on the feedback I receive with peers \\
\hline \multirow[t]{5}{*}{ Understanding } & $\begin{array}{l}\text { I ask the teaching staff questions on the parts of the } \\
\text { feedback I don't understand }\end{array}$ \\
\hline & $\begin{array}{l}\text { I aim to understand everything they are trying to tell } \\
\text { me in the feedback }\end{array}$ \\
\hline & $\begin{array}{l}\text { I associate the feedback with what I already know or } \\
\text { with prior experience }\end{array}$ \\
\hline & $\begin{array}{l}\text { When I read the feedback, if there's something I don't } \\
\text { understand, I do something to understand it: I ask } \\
\text { the teacher to clarify the aspects I don't understand, } \\
\text { I read it again or look for more information, etc. }\end{array}$ \\
\hline & I associate the feedback with the work I have done \\
\hline \multirow{3}{*}{$\begin{array}{l}\text { Identification (positive and negative aspects and } \\
\text { improving task) }\end{array}$} & I seek out information based on the feedback I receive \\
\hline & $\begin{array}{l}\text { When I read the feedback, I review the work, trying } \\
\text { to identify strengths, areas for improvement and/or } \\
\text { misunderstandings/errors in the work, but only if I } \\
\text { have to resubmit it }\end{array}$ \\
\hline & $\begin{array}{l}\text { I identify aspects to be improved and seek out infor- } \\
\text { mation from different sources to improvelenrich it }\end{array}$ \\
\hline \multirow[t]{4}{*}{ From feedback regulation of performance of task } & $\begin{array}{l}\text { I identify areas for improvement and plan future } \\
\text { actions to improve it }\end{array}$ \\
\hline & $\begin{array}{l}\text { I try to take from the feedback those aspects I need to } \\
\text { consider in the future }\end{array}$ \\
\hline & $\begin{array}{l}\text { I redo the work and check what I am doing to see if I } \\
\text { am really taking into account the aspects indicated } \\
\text { in the feedback }\end{array}$ \\
\hline & $\begin{array}{c}\text { Based on the feedback, I redo the work and check } \\
\text { whether it really includes the indicated aspects }\end{array}$ \\
\hline
\end{tabular}

Source: Own work based on Fredricks et al. (2004), (2016)

Scale: $1-7 ; 1=$ low (not frequent) and $7=$ high (very frequent)

situation of this study. The following table shows emotional engagement indicators. AEQ is a widely validated instrument used in various educational contexts, which is why it was selected (Table 2).

Regarding perception of feedback, students needed to indicate which statement best represented their view of the feedback received, each time they received the feedback: a rather positive evaluation of its assignment; a rather negative evaluation; a positive and negative evaluation to the same extent; an entirely positive evaluation, or an entirely negative evaluation.

Prior to implementing the questionnaire, it went through an internal validation process based on the participation of expert judges and piloting it with a sample of students. Internal validation was attended by seven key informants. The judges were 
Table 2 Emotional engagement indicators in online environments

\begin{tabular}{|c|c|c|c|}
\hline Activation & Valence & Emotion & Indicator \\
\hline \multirow[t]{10}{*}{ Activating } & \multirow[t]{5}{*}{ Positive (AP) } & \multirow[t]{3}{*}{ Pride } & $\begin{array}{l}\text { From the feedback received, I feel proud because my effort } \\
\text { pays off }\end{array}$ \\
\hline & & & $\begin{array}{l}\text { I am proud of the personal effort I've made to make the } \\
\text { draft, I think I've worked hard even though I haven't } \\
\text { focused on the job very well }\end{array}$ \\
\hline & & & I value and feel proud of my good preparation \\
\hline & & \multirow[t]{2}{*}{ Hope } & $\begin{array}{l}\text { I try to apply what is said in the feedback, I am optimistic } \\
\text { that everything will be fine. I think I can improve the } \\
\text { assignment }\end{array}$ \\
\hline & & & I think I can improve the assignment \\
\hline & \multirow[t]{5}{*}{ Negative (AN) } & \multirow[t]{2}{*}{ Anger } & $\begin{array}{l}\text { Ifeel angry because I spent a lot of time on the assign- } \\
\text { ment }\end{array}$ \\
\hline & & & I think the criteria were unfair \\
\hline & & \multirow[t]{2}{*}{ Anxiety } & When reading the feedback I got nervous \\
\hline & & & I'm worried if I can do what they tell me through feedback \\
\hline & & Shame & I am ashamed of my poor preparation \\
\hline \multirow[t]{5}{*}{ Deactivating } & \multirow[t]{2}{*}{ Positive (DP) } & \multirow[t]{2}{*}{ Relief } & I'm relieved, at least I haven't suspended yet \\
\hline & & & I feel relieved because I see that I am well on my way \\
\hline & \multirow[t]{3}{*}{ Negative (DN) } & \multirow[t]{2}{*}{ Hopelessness } & I would rather leave and not continue with the assignment \\
\hline & & & I lost all hope of doing well \\
\hline & & Helplessness & $\begin{array}{l}\text { I started to think that no matter how hard I try I won't get } \\
\text { better }\end{array}$ \\
\hline
\end{tabular}

Own work based on The Achievement Emotions Questionnaire (AEQ), Pekrun et al. (2011)

Scale: $1-7 ; 1=$ low (not frequent) and $7=$ high (very frequent)

five university professors within the department of Educational Psychology and considered experts in evaluation and feedback research, and two professors who were experts in Methodology. Disagreements between the experts consulted, and the suggested improvements, were discussed within the research group and introduced in the final version of the questionnaire.

In the entirety of the quasi-experimental sample the Cronbach's Alpha (CA) values are 0.71 which provides reasonable internal consistency (Taber, 2018). The arguments about the internal validation process and the statistical validity data allow us to substantiate the reliability of the instrument.

\subsection{Data analysis procedure}

Data analysis was carried out using two basic procedures: (1) univariate and bivariate descriptive statistics and (2) bivariate inferential statistics. The statistical analysis was carried out with SPSS (v21).

Regarding point 1, univariate descriptive statistics were used producing basic descriptors as means (M) and standard deviations (SD) as well as position analysis (quartiles) and comparing experimental groups. Second (2) the bivariate inferential 
analysis, before the hypothesis contrast was addressed, the Kolmogorov-Smirnov normality test (K-S) was performed as well as other contrasts, which were positive, whereby, for the hypothesis contrasts, non-parametric tests were carried out according to the comparisons that have been made. Each test is referenced in the corresponding tables.

\section{Results}

\subsection{Research question 1}

As shown in Table 3, at the end of the process, there were no statistically significant differences between the different experimental groups in their perceived valence of the final feedback. In both groups (quasi-experimental and control), most students perceived feedback as positive.

In this way, the relationships between the variable perception of feedback valence and emotional and cognitive engagement can be attributed in a single way to the relationship between variables during the intermediate moment and not to the different distribution of it in the groups in terms of valence of feedback.

\subsection{Research question 2}

The results suggest that there was a statistically significant relationship between the perceived valence of the feedback, in relation to the draft assignment, and the emotional engagement of students with the feedback. As can be seen in (Fig. 2), students who received feedback after submitting the draft and who considered that its content was both positive and negative, experienced lower intensity of positive activating emotions, a higher intensity of negative activating emotions, and different intensities of positive deactivating emotions, compared to students who perceived feedback as only positive. Likewise, students who perceived

Table 3 Perceived valence of the feedback once received in both the quasi-experimental group and the control group

\begin{tabular}{|c|c|c|c|c|c|c|}
\hline & \multicolumn{4}{|c|}{ Quasi-experimental group $^{a}$} & \multirow{2}{*}{\multicolumn{2}{|c|}{$\frac{\text { Control group }^{b}}{\text { Final feedback }}$}} \\
\hline & \multicolumn{2}{|c|}{ Initial feedback } & \multicolumn{2}{|c|}{ Final feedback } & & \\
\hline & $\mathrm{n}$ & $\%$ & $\mathrm{n}$ & $\%$ & $\mathrm{n}$ & $\%$ \\
\hline Totally negative, or rather negative & 4 & 3.6 & 35 & 31.5 & 19 & 23.8 \\
\hline Positive and negative & 35 & 31.5 & 27 & 24.3 & 22 & 27.5 \\
\hline Rather positive or totally positive & 72 & 64.9 & 49 & 44.1 & 39 & 48.8 \\
\hline Total & 111 & 100 & 111 & 100 & 80 & 100 \\
\hline
\end{tabular}

${ }^{\text {a }}$ Signal test $(Z=-5.284 ; \mathrm{p}<0.001)$ and marginal homogeneity test $(\mathrm{HM}$ typified $=6.2089 ; \mathrm{p}<0.001)$

${ }^{\mathrm{b}} \chi^{2}(2, \mathrm{~N}=191)=1.393, \mathrm{p}=.498$ 


\begin{tabular}{|c|c|c|c|}
\hline \multirow[t]{2}{*}{ Emotions } & \multicolumn{3}{|c|}{ Feedback valence perception in relation to draft } \\
\hline & Positive & & Positive and negative \\
\hline \multirow[t]{3}{*}{ Positive activating } & Hope & & Hope \\
\hline & & $>$ & \\
\hline & Pride & & Pride \\
\hline \multirow[t]{2}{*}{ Negative activating } & Anxiety & $<$ & Anxiety \\
\hline & Shame & & Shame \\
\hline \multirow[t]{2}{*}{ Positive deactivating } & $\begin{array}{l}\text { Relief by identifying that } \\
\text { they were on the right } \\
\text { path. }\end{array}$ & $>$ & $\begin{array}{l}\text { Relief by identifying that they were } \\
\text { on the right path. }\end{array}$ \\
\hline & $\begin{array}{l}\text { Relief that they have not } \\
\text { yet failed. }\end{array}$ & $<$ & Relief that they have not yet failed. \\
\hline Negative deactivating & Helplessness & $<$ & Helplessness \\
\hline
\end{tabular}

Fig. 2 Intensity of experimentation of emotions depending on the perception of the valence of feedback after the draft. Quasi-experimental group

feedback as both positive and negative, experienced more intensely some negative deactivating emotions, even though in this case, the intensity in both groups was low.

Indeed, the Mann-Whitney test was significant in those students who considered the received feedback positive showed greater intensity in the experience of positive activating emotions (see Fig. 2) than students who perceived feedback as both positive and negative $(Z=-3.716 ; p<0.001)$. Specifically in the hope of being able to improve $(Z=-2.545 ; p<0.05)$, pride for the effort made $(Z=-4.613 ; p<0.001)$ and for good preparation $(\mathrm{Z}=-3.891 ; \mathrm{p}<0.001)$. In turn, they showed significantly lower values for the intensity at which they experienced negative activating emotions $(\mathrm{Z}=-4.576 ; \mathrm{p}<0.001)$, especially less anxiety over whether or not they would do well when implementing feedback $(Z=-4.832 ; p<0.001)$, less nerves $(Z=-3.721$; $\mathrm{p}<0.001)$ and less shame due to lack of preparation $(Z=-4.194 \mathrm{p}<0.001)$. Students who perceived the feedback as positive also showed differences in the level at which they experienced positive deactivating emotions, compared to those who considered the feedback to be both positive and negative. Thus, they experienced greater relief because they felt they were well on track $(Z=-5.430 ; p<0.001)$ and a smaller sense of relief because they have not yet failed $(Z=-5.244 ; p<0.001)$. They also experienced some negative deactivating emotions with less intensity. Thus, helplessness was experienced less intensely in the group of students who perceived feedback as positive, although in both groups the intensity with which helplessness was experienced was low.

Referring to the results relating to the relationship between the perception of feedback as negative after the draft was delivered and emotional engagement, it was not possible to provide data, due to the low frequency with which students perceived feedback as negative. 
Regarding feedback provided at the end of the assignment, the results suggested that there was no significant relationship between the perception of feedback received and emotional engagement with it. The Kruskal-Wallis test (as well as the different comparisons 2 to 2 with the Mann-Whitney test) was negative in both the quasi-experimental and control groups.

In summary, in terms of the relationship between the perceived valence of the feedback received and emotional engagement, significant correlations were only identified when the feedback was provided during the assignment, after delivering the draft, and not at the end of it.

\subsection{Research question 3}

Unlike emotional engagement with feedback, there was no statistically significant relationship between the perception of feedback received and the cognitive engagement of students in receiving feedback after the draft was submitted. So, perceiving feedback as positive or perceiving both positive and negative feedback did not imply a different cognitive engagement with the feedback.

Both the Mann-Whitney test (differentiating students who believed they had received feedback regarding the draft that was both positive and negative or positive) and the Kruskal-Wallis test (separating students according to whether the feedback was perceived as both positive and negative, more positive than negative or totally positive) proved to not be significant.

However, as can be seen in (Table 4), at the end of the assignment, a significant relationship was observed between the perception of feedback received and cognitive engagement with feedback in the quasi-experimental group. In contrast, in the control group, there was no relationship between the valence attributed to the feedback and the cognitive engagement with it.

The Kruskal-Wallis test (see Table 4) was positive in the quasi-experimental group in relation to not using the feedback $\left(\mathrm{X}^{2}(2)=12.156 ; p=0.002\right)$, as well as reading feedback $\left(\mathrm{X}^{2}(2)=8.856 ; p=0.012\right)$ and understanding feedback $\left(\mathrm{X}^{2}(2)\right.$ $=6.829 ; p=0.033)$. Specifically, in this group of students, those who perceived the final feedback as negative are more likely to ignore it and do nothing, as opposed to those who perceive it as positive (see Fig. 3). They are also the ones that were less engaged through reading and understanding. In the quasi-experimental group, students who perceived both positive and negative final feedback were those who most discussed the feedback with the lecturer $\left(\mathrm{X}^{2}(2)=9.012 ; p=.011\right)$ and peers $\left(\mathrm{X}^{2}(2)=9415 ; p=0.009\right)$. In addition, students who perceived feedback as positive (totally or almost totally) excelled in searching for information based on the feedback received $\left(\mathrm{X}^{2}(2)=9.400 ; p=0.009\right)$.

In summary, the results have identified a relationship between the perceived valence of the feedback and engagement with the feedback in the quasi-experimental group (see Fig. 3) and not in the control group. This relationship between feedback perception and engagement was seen in emotional engagement with feedback after the draft and cognitive engagement with feedback at the end of the assignment. 
Table 4 Relationship between the perceived valence of the feedback received and cognitive engagement with the final feedback. Comparison between quasi-experimental group and control group

\begin{tabular}{|c|c|c|c|c|}
\hline \multicolumn{5}{|l|}{ Ranks } \\
\hline & & & $\mathrm{N}$ & Mean rank \\
\hline \multirow[t]{20}{*}{ Quasi-experimental group } & \multirow[t]{4}{*}{ Not use of feedback } & Negative & 33 & 64.92 \\
\hline & & Negative + Positive & 27 & 52.76 \\
\hline & & Positive & 49 & 49.55 \\
\hline & & Total & 109 & \\
\hline & \multirow[t]{4}{*}{ Reading } & Negative & 34 & 43.03 \\
\hline & & Negative + Positive & 27 & 64.85 \\
\hline & & Positive & 49 & 59.00 \\
\hline & & Total & 110 & \\
\hline & \multirow[t]{4}{*}{ Understanding } & Negative & 34 & 44.47 \\
\hline & & Negative + Positive & 27 & 65.33 \\
\hline & & Positive & 47 & 55.53 \\
\hline & & Total & 108 & \\
\hline & \multirow[t]{4}{*}{ Identification } & Negative & 34 & 47.88 \\
\hline & & Negative + Positive & 27 & 55.85 \\
\hline & & Positive & 49 & 60.59 \\
\hline & & Total & 110 & \\
\hline & \multirow{4}{*}{$\begin{array}{c}\text { From feedback regulation } \\
\text { of performance of task }\end{array}$} & Negative & 33 & 49.35 \\
\hline & & Negative + Positive & 27 & 60.83 \\
\hline & & Positive & 49 & 55.59 \\
\hline & & Total & 109 & \\
\hline \multirow[t]{20}{*}{ Control group } & \multirow[t]{4}{*}{ Not use of feedback } & Negative & 18 & 42.03 \\
\hline & & Negative + Positive & 22 & 34.55 \\
\hline & & Positive & 38 & 41.17 \\
\hline & & Total & 78 & \\
\hline & \multirow[t]{4}{*}{ Reading } & Negative & 19 & 40.21 \\
\hline & & Negative + Positive & 22 & 48.09 \\
\hline & & Positive & 37 & 34.03 \\
\hline & & Total & 78 & \\
\hline & \multirow[t]{4}{*}{ Understanding } & Negative & 17 & 45.35 \\
\hline & & Negative + Positive & 21 & 33.71 \\
\hline & & Positive & 35 & 34.91 \\
\hline & & Total & 73 & \\
\hline & \multirow[t]{4}{*}{ Identification } & Negative & 18 & 36.86 \\
\hline & & Negative + Positive & 22 & 42.66 \\
\hline & & Positive & 36 & 36.78 \\
\hline & & Total & 76 & \\
\hline & \multirow{4}{*}{$\begin{array}{c}\text { From feedback regulation } \\
\text { of performance of task }\end{array}$} & Negative & 19 & 37.18 \\
\hline & & Negative + Positive & 20 & 37.03 \\
\hline & & Positive & 38 & 40.95 \\
\hline & & Total & 77 & \\
\hline
\end{tabular}


Table 4 (continued)

\begin{tabular}{cllllll}
\hline Test statistics $^{\mathrm{a}}$ & \multicolumn{1}{c}{$\begin{array}{l}\text { Not use of } \\
\text { feedback }\end{array}$} & Reading & Understanding & Identification & Regulation \\
\hline $\begin{array}{c}\text { Quasi-experi- } \\
\text { mental group }\end{array}$ & Chi-Square & 12.156 & 8.856 & 6.829 & 3.556 & 2.029 \\
& df & 2 & 2 & 2 & 2 & 2 \\
& Asymp. Sig. & .002 & .012 & .033 & .169 & .363 \\
\hline Control group & Chi-Square & 1.938 & 5.574 & 3.506 & 1.106 & .572 \\
& df & 2 & 2 & 2 & 2 & 2 \\
& Asymp. Sig. & .379 & .062 & .173 & .575 & .751 \\
\hline
\end{tabular}

${ }^{\text {a }}$ Kruskal Wallis Test

* Additional data are provided in Online Resource 2

\subsection{Research question 4}

The results pointed to a relationship between how students in the quasi-experimental group perceived feedback and the interrelationship between emotional and cognitive engagement.

The results demonstrate a significant correlation between emotional and cognitive engagement with students who perceived the feedback provided in relation to the draft with both positive and negative elements (see Fig. 4). On the one hand, regulation (higher level of cognitive engagement) was clearly reinforced if hope (a positive activating emotion) was experienced $(\mathrm{r}(34)=0.431, \mathrm{p}=0.011)$. Identification of elements that were positive, negative, or need improvement in terms of the assignment were also strongly reinforced if hope (positive activating emotion) was experienced $(\mathrm{r}(34)=0.508, \mathrm{p}=0.002)$ and reduced if anger (negative activating emotions) was experienced $(\mathrm{r}(34)=-0.397, \mathrm{p}=0.020)$. Attempts to understand feedback were reduced by feeling relief (positive deactivating emotions)

\begin{tabular}{|c|c|}
\hline Perceived valence of the final feedback & Cognitive engagement \\
\hline Negative & $\begin{array}{l}\text { Ignored feedback received. Did not read the feedback and did } \\
\text { not attempt to understand it }\end{array}$ \\
\hline Positive and negative & Discussed feedback with faculty and peers \\
\hline Positive & $\begin{array}{l}\text { Read and tried to understand feedback. Searched for } \\
\text { information based on feedback received }\end{array}$ \\
\hline
\end{tabular}

Fig. 3 Relationship between the perception of the valence of the final feedback and the cognitive engagement with the feedback. Quasi-experimental group 


$\begin{array}{cccc}\text { If students perceive } & \text { and they get emotionally } & \text { and they get emotionally } & \text { they get cognitively engaged } \\ \text { feedback as ... } & \text { engaged through } & \text { engaged through } & \text { through }\end{array}$

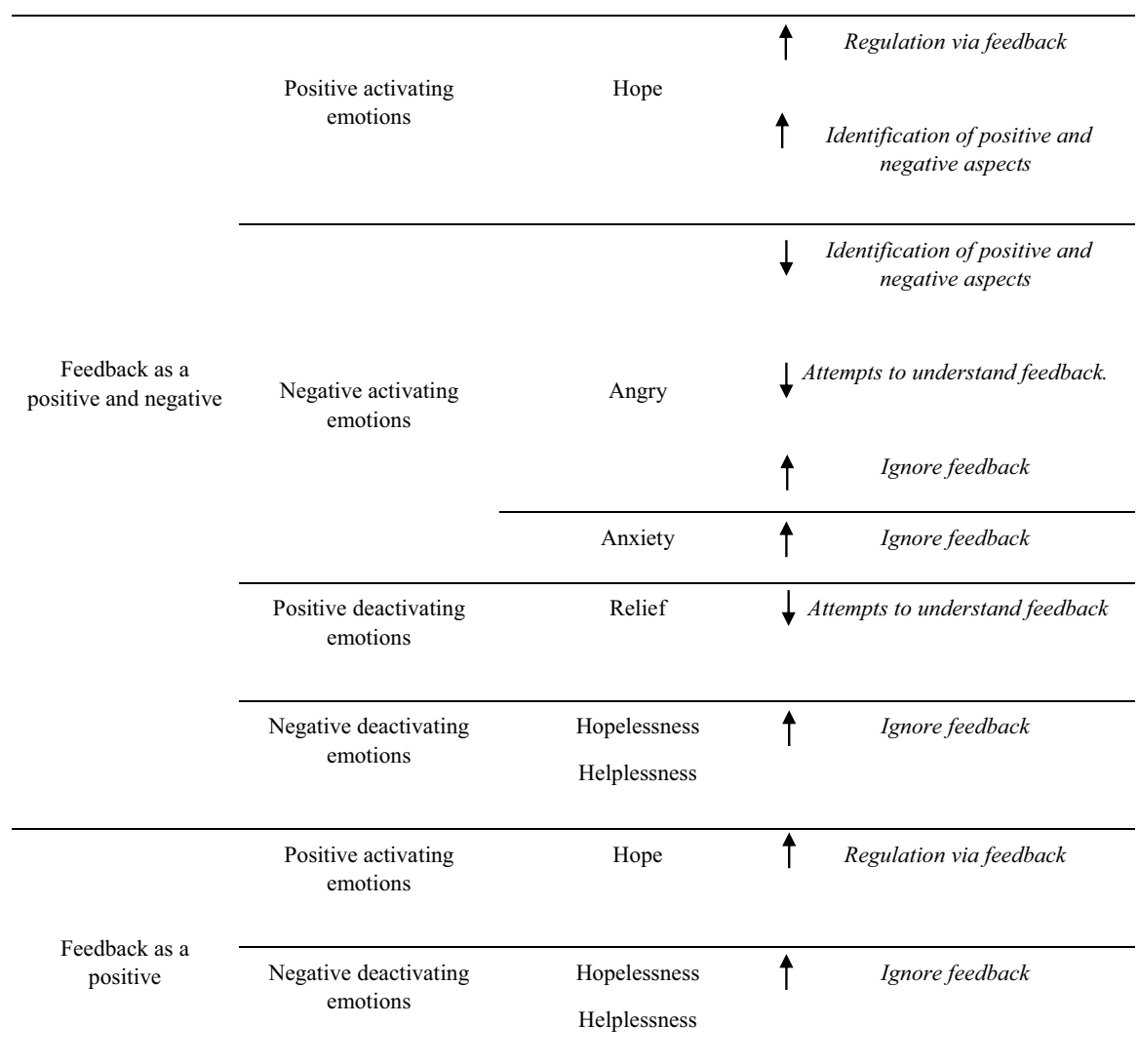

*Summary figure of the main results. Additional data (tables with the detailed statistics) are provided in Online Resource 3.

Fig. 4 Relationship between feedback perception regarding draft and emotional engagement and cognitive engagement with feedback

$(\mathrm{r}(34)=-0.421, \mathrm{p}=0.013)$ and were also reduced by feeling angry (negative activating emotions) $(\mathrm{r}(34)=-0.397, \mathrm{p}=0.020)$. Feedback was largely ignored if students felt angry $(\mathrm{r}(34)=0.345, \mathrm{p}=0.045)$ and if students were experiencing anxiety (negative activating emotions) about whether they would be able to implement feedback $(r(34)=0.371, p=0.031)$. Likewise, the students also ignored the feedback if they experienced negative deactivating emotions, such as hopelessness in the form of desire to abandon $(r(34)=0.348, p=0.047)$, or belief that they would not know how to implement the feedback $(\mathrm{r}(34)=0.350, \mathrm{p}=0.043)$ and helplessness in the form of considering that no matter how hard they tried they could not improve $(\mathrm{r}(34)=0.348, \mathrm{p}=0.047)$. 
Among students who perceived feedback after the draft as basically positive, the correlation between emotional and cognitive engagement was lower. Thus, there was greater cognitive engagement with feedback linked to the processes of using feedback to regulate the performance of the assignment if the students felt confident they would be able to improve (positive activating emotions) $(r(71)=0.291$, $\mathrm{p}=0.014$ ). The results also suggested that, even if the feedback was perceived as positive, students experienced negative deactivating emotions. For example, if they felt hopelessness $(\mathrm{r}(70)=-0.374, \mathrm{p}=0.001)$ or a lack of confidence in their abilities $(\mathrm{r}(70)=-0.420, \mathrm{p}<0.000)$ they stopped using the feedback.

Since no significant relationships were identified between how the final feedback was perceived and the emotional engagement with the feedback, we have not proceeded to present the results on how it mediates cognitive engagement in relation to the final feedback.

\section{Discussion and conclusions}

The objective of this study was threefold. First, to understand the relationship between the perceived valence of feedback (positive, negative, positive and negative valence) by students in online environments and the way in which they engaged with feedback. Second, to examine the role of creating the conditions for students to use feedback in order to improve the assignment performed. And third, to analyse the influence that emotional engagement with feedback has on cognitive engagement based on how feedback was perceived. In accordance with the above research, this study confirms the complexity and multidimensionality required to analyse engagement in online environments. This study provides scientific evidence on the relationships between the possibilities of resubmission and the perception of the valence of feedback with feedback engagement. In addition, it was conducted with larger samples than previous research, which gives solidity to the results obtained. Finally, this study goes one step further and places the results in a context not linked to the study of L2 but rather in argumentative written tasks on content linked to learning disabilities. The main results are discussed in detail below, and the implications for teaching and learning processes in online environments are explained.

The results of this study suggest that the students' perception of the valence of feedback is not influenced by the fact that they received feedback during the process of carrying out the assignment. The results show that there were no significant differences in the way feedback was perceived between the control group and the quasiexperimental group. Although there were no differences in the perceived valence of the feedback, there were differences in the impact that perception had on students' engagement with the feedback received. In the group of students that did not receive feedback while carrying out the assignment, there was not a significant relationship between how students perceived feedback with how they engaged with it. In contrast, this relationship was identified in the group of students who received feedback during the assignment. The results indicate that the possibility of using feedback throughout the process of the assignment is related to the level of importance that 
students finally give to feedback during the learning process. When students only receive feedback after the activity is finished, they do not see the value of applying it to new activities (Ali et al., 2018; Yorke, 2003). Students' perception of the purpose of feedback is important for their engagement (Winstone, et al., 2017; Noon \& Eyre, 2020). Considering feedback only at the end of the assignment process does not promote proactive engagement with feedback (Boud \& Molloy, 2012; Noon \& Eyre, 2020), since students may not perceive it as useful.

Likewise, designing opportunities to implement the feedback in online environments can be a relevant factor in influencing students' perception of feedback as a learning tool. The results support the fact that the characteristics that students can attribute to feedback during the learning process influence how they engage with it. Results also point to the importance of designing situations in which students can review the assignment being performed using the feedback received to promote what Sutton (2012) and Winstone and Carless (2019) call the epistemological dimension of literacy with feedback.

The results also revealed a significant relationship between the perceived valence of the feedback and emotional engagement with the feedback during the execution of the assignment and not at the end of the assignment. Our data illustrated that when students perceived the feedback received during the assignment process as positive, they showed greater intensity in the positive activating emotions than those who perceived the feedback with a negative component (when students perceived the feedback received both positive and negative). They experienced confidence in improvement, pride in good preparation, and the effort made more intensely. Experiencing these emotions can positively affect self-efficacy and self-perception as a learner in the long term. As mentioned, the lecturers were trained to provide constructive feedback based on providing opportunities and support for improvement. In this sense, although there was no perception of feedback as negative, the results suggest that when feedback is perceived with some negative components it generates positive activating emotions with less intensity and could influence the perceived self-efficacy of the students (Gibbs \& Simpson, 2004; Sargeant et al., 2008; Rowe, 2017). In fact, the results also demonstrated the fact that sometimes students who perceived feedback as positive and negative also experienced hope, although to a lesser extent than when they perceived feedback as positive. Our results also converged with those of Pekrun et al. (2014) in which students reported having experienced significantly greater hope and pride when they expected self-referential feedback (i.e., focused on the level of progress and not just the grade). According to Pekrun et al. (2014), providing constructive feedback with elements for improvement on the draft generated a greater sense of control of future results in students. In this same sense, Fong et al. (2016) points out that the feedback that highlights improvement or elements for improvement is associated with a greater intensity of hope.

These results allowed us to emphasize the importance of awareness of the emotions experienced in relation to feedback in online environments and to be able to regulate them. The form that feedback takes during the process can be an instrument to promote a certain level of emotional engagement in relation to the feedback and a support for the regulation of emotions during the learning process. As Fong et al. (2016) point out, awareness of the emotions that students 
experience when they receive feedback can help teachers facilitate emotional regulation toward learning experiences over which students have a feeling of control. Winstone and Carless (2020) indicate that the ability to manage emotions in feedback situations does not mean that students do not experience negative emotions. Rather, they can regulate them appropriately and go further in the execution of their task or assignment. Helping students to regulate their emotions through feedback becomes particularly relevant considering the results indicating that during the performance of the task (after the draft is delivered) in online environments, how the feedback is perceived is related to how emotional engagement is linked to certain levels of cognitive engagement. Indeed, the results showed a higher level of cognitive engagement with feedback when students experienced positive activation emotions after perceiving feedback as positive or perceiving it as positive with some negative elements than when they experienced other types of emotions. When they experienced negative emotions, either activating or deactivating emotions, the level of cognitive engagement with feedback was lower.

As Winstone and Carless (2020) make note of, meaningful engagement with feedback processes can be "obscured by emotional static" (Chanock, 2000 cited in Winstone \& Carless, 2020, p. 27) where emotions can impede cognitive processing of feedback exchanges. Our study shows that emotions not only can impede but also boost cognitive processing of feedback.

According to Fong et al. (2016), understanding the type of emotions that are induced in students based on how they perceive feedback and the impact of these emotions on cognitive engagement, highlights the importance of helping students become aware of these [emotions] and providing them with emotional regulation strategies to promote cognitive engagement in a given direction.

Lastly, the results showed that when students could resubmit their assignment, implementing feedback received during the assignment in online settings, their perception of the feedback provided to them after the assignment was completed influenced their cognitive engagement with the feedback. This relationship did not occur in the case of students in the control group. This result reinforced the interpretation, noted above, that providing opportunities to use feedback during the process influenced the importance of feedback and a higher level of engagement with feedback, in online environments. The results highlighted the importance of also considering students' perception of feedback at the end of the process, since how they perceived feedback affected their degree of cognitive engagement with feedback. Despite the feedback being constructive, it is important for students to perceive it as positive to promote a higher level of cognitive engagement with feedback, in online environments.

In this regard, considering the importance of support during the learning process in online environments for the persistence of students in the programs (Rutz \& Ehrlich, 2016) and the relevant role that feedback plays as an instrument of support, perception of feedback needs to be considered as a fundamental element in promoting persistence.

In line with the findings of our study, the following are implications for learning and instruction. 
Studies point to the importance of providing feedback throughout the process of the assignment to promote engagement with feedback. However, in online environments, it is not enough to provide feedback during the activity process; it is also essential to understand how students perceive the feedback they receive. This perception will influence how they engage emotionally with the feedback, and this will at the same time affect cognitive engagement with feedback, i.e., how students use feedback to regulate the process of executing the assignment.

The way feedback is provided during the process, in online environments, will influence the perception of feedback and therefore how students are engaged. Feedback, in this case, can be an instrument that helps students become aware of their emotions during the learning process and help them regulate themselves emotionally during learning.

It is necessary to promote a positive perception of feedback by students (which is not the same as saying that feedback must be positive, but rather that students perceive feedback as positive) to promote positive activating emotions that influence at a higher level of cognitive engagement with feedback.

Finally, we would like to point out some challenges involved in providing dialogic and formative feedback by considering how students perceive the feedback they receive and the factors that influence their engagement with the feedback. While providing feedback during the development of the activity in online environments is fundamental to promote students' learning regulation competencies, it can considerably increase the workload of teachers and students. For this, it is necessary to promote an institutional culture that promotes the development of assessment and feedback literacy of both teachers and students, as well as techno-pedagogical support, equipment, and infrastructures.

\section{Limitations}

This research is relevant because it empirically investigates the relationship between how students experience and perceive feedback in a real assessment situation, in an online environment, and their emotional and cognitive engagement. Thus, our study contributes to and supports the body of studies conducted in which either feedback was anticipated (Pekrun et al., 2014), in imaginary feedback situations (Fong et al., 2016) or where real feedback was studied but not the students' perception of it (Kim \& Lee, 2019).

However, although our study made it possible to provide clear scientific evidence, there are some limitations that we must consider.

First, the results of this study must be taken with caution, because this study was carried out with specific groups taking an elective course within a Master's degree in Learning Difficulties, at a specific university, with an online teaching and learning environment.

Second, there are variables that may influence the results and have not been considered in the present study but will be the subject of further research. This refers to variables that may influence interpretation and/or engagement with feedback such as students' motivational orientation, their attribute patterns, perception of competence 
or self-efficacy, the value they confer to the assignment, the perception of difficulty of the task, as well as the correspondence between the type of feedback and the perception of feedback by students.

A third limitation concerns data collection instruments. The data were selfinformed using responses to a questionnaire, which may lead to students not openly showing their emotions, or that cognitive engagement is self-informed and not an objective measurement of actual cognitive use of the feedback. In further research, it could add more information to combine these data with those collected using other instruments and information collection pathways (physiological, etc.). Regarding the limitation of the data collection instrument, another limitation concerns the selection of emotions, and items relating to them, when studying emotional engagement. To measure emotional engagement, items were selected that were adapted to the context from the Achievement Emotions Questionnaire (Pekrun et al., 2011). The goal was to maintain the sample because during the course, data were collected from the students answering different questionnaires, although the results presented relate to the first assignment. A longer questionnaire would not have allowed us to collect results with such a large sample.

\section{Future research}

In this study, we do not present results regarding the value students assign to the assignment taking place or to their goals and feelings of competence, all of which are aspects that can mediate the emotional response to feedback. These elements will be the aim of further studies.

We have focused on how the perception of feedback could be related to these different levels of engagement. Necessary future research should address the extent to which the characteristics of the feedback provided, and the demanding characteristics of the task, lead to engagement at the different levels indicated. It would also be interesting to relate the characteristics of the feedback to the perception of the feedback informed by the students and to study possible variables (attributed patterns, perception of competence, value of the task, etc.) that can influence that perception and subsequent engagement.

As we have pointed out, in this article we present the results of the analysis relating to an assignment within the framework of a Master's degree course. This study is part of broader research with the objective of capturing the evolution of student engagement with the feedback they receive and the dynamics of this engagement, to understand the factors that promote and hinder it and to study the impact it has on the learning process of students.

Authors' contributions Research presented has been carried out within Feed2Learn Research Group. The four authors are part of this group and have worked to: (1) gather data, (2) analyse it and (3) discuss the results obtained and elaborate the conclusions. Rosa M Mayordomo was a major contributor in writing the manuscript. 
Funding Open Access funding provided thanks to the CRUE-CSIC agreement with Springer Nature.

\section{Declarations}

Funding This research was supported by the Project "Engaging students with feedback for learning in online environments (ON-Feed). Funded by Spanish Ministry of Science, Innovation and Universities. PGC2018-098552-B-I00.

Ethics approval The project in which this study is framed was approved by the Ethics Committee of the Open University of Catalonia. Institutional ethical approval was obtained for the use of the data and the approaching of individuals. Likewise, Informed consent for the research was obtained from the teaching staff and students.

Conflicts of interest/Competing interests The authors have no relevant financial or non-financial interests to disclose.

Availability of data and material The datasets used and analysed during the current study are available from the corresponding author on reasonable request.

Open Access This article is licensed under a Creative Commons Attribution 4.0 International License, which permits use, sharing, adaptation, distribution and reproduction in any medium or format, as long as you give appropriate credit to the original author(s) and the source, provide a link to the Creative Commons licence, and indicate if changes were made. The images or other third party material in this article are included in the article's Creative Commons licence, unless indicated otherwise in a credit line to the material. If material is not included in the article's Creative Commons licence and your intended use is not permitted by statutory regulation or exceeds the permitted use, you will need to obtain permission directly from the copyright holder. To view a copy of this licence, visit http://creativecommons.org/licen ses/by/4.0/.

\section{References}

Ali, N., Ahmed, L., \& Rose, S. (2018). Identifying predictors of students' perception of and engagement with assessment feedback. Active Learning in Higher Education, 19(3), 239-251. https://doi.org/10. $1177 / 1469787417735609$

Boud, D. \& Molloy, E. (2013). What is the problem with feedback? In D. Boud, \& E. Molloy, (Eds.), Feedback in higher and professional education (1-10). Routledge.

Carless, D. (2006). Differing perceptions in the feedback process. Studies in Higher Education, 31(2), 219-233. https://doi.org/10.1080/03075070600572132

Carless, D. (2015). Exploring learning-oriented assessment processes. Higher Education, 69, 963-976. https://doi.org/10.1007/s10734-014-9816-Z

Carless, D., \& Boud, D. (2018). The development of student feedback literacy: Enabling uptake of feedback. Assessment \& Evaluation in Higher Education, 43(8), 1315-1325. https://doi.org/10.1080/ 02602938.2018.1463354

Evans, C. (2013). Making sense of assessment feedback in higher education. Review of Educational Research, 83(1), 70-120. https://doi.org/10.3102/0034654312474350

Fernández-Garcia, P., Vallejo-Seco, G., Livacic-Rojas, P. E., \& Tuero-Herrero, E. (2014). Validez Estructurada para una investigación cuasi-experimental de calidad. Se cumplen 50 años de la presentación en sociedad de los diseños cuasi-experimentales. Anales de Psicología, 30(2), 756-772. https://doi. org/10.6018/analesps.30.2.166911

Fisher, R., Cavanagh, J., \& Bowles, A. (2011). Assisting transition to university: Using assessment as a formative learning tool. Assessment and Evaluation in Higher Education, 36(2), 225-237. https:// doi.org/10.1080/02602930903308241 
Fong, C. J., Warner, J. R., Williams, K. M., Schallert, D. L., Chen, L.-H., Williamson, Z. H., \& Lin, S. (2016). Deconstructing constructive criticism: The nature of academic emotions associated with constructive, positive, and negative feedback. Learning and Individual Differences, 49, 393-399. https://doi.org/10.1016/j.lindif.2016.05.019

Fong, C. J., Schallert, D. L., Williams, K. M., Williamson, Z. H., Warner, J. R., Lin, S., \& Kim, Y. W. (2018). When feedback signals failure but offers hope for improvement: A process model of constructive criticism. Thinking Skills and Creativity, 30, 42-53. https://doi.org/10.1016/j.tsc.2018.02. 014

Fredricks, J. A., Blumenfeld, P. C., \& Paris, A. C. (2004). School engagement: Potential of the concept, state of the evidence. Review of Educational Research, 74(1), 59-109. https://doi.org/10.3102/ 00346543074001059

Fredricks, J. A., Wang, J., Linn, J., Hofkens, T. L., Sung, H., Parr, A., \& Allerton, J. (2016). Using qualitative methods to develop a survey measure of math and science engagement. Learning and Instruction, 43, 5-15. https://doi.org/10.1016/j.learninstruc.2016.01.009

Gamlem, S. M., \& Smith, K. (2013). Student perceptions of classroom feedback. Assessment in Education: Principles, Policy \& Practice, 20(2), 150-169. https://doi.org/10.1080/0969594X.2012. 749212

Gibbs, G., \& Simpson, C. (2004). Conditions under which assessment supports students' learning. Learning and Teaching in Higher Education, 1, 3-31. https://doi.org/10.1007/978-3-8348-9837-1

Guasch, T., Espasa, A., Alvarez, I. M., \& Kirschner, P. A. (2013). Effects of feedback on collaborative writing in an online learning environment. Distance Education, 34(3), 324-338. https://doi.org/10. 1080/01587919.2013.835772

Hargreaves, E. (2013). Inquiring into children's experiences of teacher feedback: Reconceptualising assessment for learning. Oxford Review of Education, 39(2), 229-246. https://doi.org/10.1080/ 03054985.2013 .787922

Hattie, J., \& Timperley, H. (2007). The power of feedback. Review of Educational Research, 77(1), 81-112. https://doi.org/10.3102/003465430298487

Havnes, A., Smith, K., Dysthe, O., \& Ludvigsen, K. (2012). Formative assessment and feedback: Making learning visible. Studies in Educational Evaluation, 38(1), 21-27. https://doi.org/10.1016/j.stueduc. 2012.04.001

Hepplestone, S., Holden, G., Irwin, B., Parkin, H. J., \& Thorpe, L. (2011). Using technology to encourage student engagement with feedback: A literature review. Research in Learning Technology, 19(2), 117-127. https://doi.org/10.3402/rlt.v19i2.10347

Jarrell, A., Harley, J. M., Lajoie, S., \& Naismith, L. (2017). Success, failure and emotions: Examining the relationship between performance feedback and emotions in diagnostic reasoning. Educational Technology Research and Development, 65(5), 1263-1284. https://doi.org/10.1007/ s11423-017-9521-6

Kim, E. J., \& Lee, K. R. (2019). Effects of an examiner's positive and negative feedback on self-assessment of skill performance, emotional response, and self-efficacy in Korea: A quasi-experimental study. BMC Medical Education, 19, 142. https://doi.org/10.1186/s12909-019-1595-x

Noon, M. R., \& Eyre, E. L. J. (2020). A feedforward approach to teaching, learning and assessment in an undergraduate sports science module. Journal of Hospitality, Leisure, Sport \& Tourism Education, 27, 100257. https://doi.org/10.1016/j.jhlste.2020.100257

Parkin, H. J., Hepplestone, S., Holden, G., Irwin, B., \& Thorpe, L. (2012). A role for technology in enhancing students' engagement with feedback. Assessment \& Evaluation in Higher Education, 37(8), 963-973. https://doi.org/10.1080/02602938.2011.592934

Pekrun, R. (2006). The control-value theory of achievement emotions: Assumptions, corollaries, and implications for educational research and practice. Educational Psychology Review, 18(4), 315-341. https://doi.org/10.1007/s10648-006-9029-9

Pekrun, R., Goetz, T., Frenzel, A. C., Barchfeld, P., \& Perry, R. P. (2011). Measuring emotions in students' learning and performance: The Achievement Emotions Questionnaire (AEQ). Contemporary Educational Psychology, 36, 36-48. https://doi.org/10.1016/j.cedpsych.2010.10.002

Pekrun, R., Cusack, A., Murayama, K., Elliot, A. J., \& Thomas, K. (2014). The power of anticipated feedback: Effects on students' achievement goals and achievement emotions. Learning and Instruction, 29, 115-124. https://doi.org/10.1016/j.learninstruc.2013.09.002

Price, M., Handley, K., \& Millar, J. (2011). Feedback: Focusing attention on engagement. Studies in Higher Education, 36(8), 879-896. https://doi.org/10.1080/03075079.2010.483513 
Rowe, A.D. (2017). Feelings about feedback: The role of emotions in assessment for learning. In: David Carless, Susan M. Bridges, Cecilia Ka Yuk Chan, Rick Glofchesk (eds.), Scaling up assessment for learning in higher education (pp. 159-172). Springer, Springer Nature.

Rutz, E., \& Ehrlich, S. (2016, June). Increasing learner engagement in online learning through use of interactive feedback: Results of a pilot study. In 2016 ASEE annual conference \& exposition. New Orleans, Louisiana. 10.18260/p.25672.

Ryan, T., \& Henderson, M. (2018). Feeling feedback: Students' emotional responses to educator feedback. Assessment \& Evaluation in Higher Education, 43(6), 880-892. https://doi.org/10.1080/02602 938.2017.1416456

Sargeant, J., Mann, K., Sinclair, D., Van Der Vleuten, C., \& Metsemakers, J. (2008). Understanding the influence of emotions and reflection upon multi-source feedback acceptance and use. Advances in Health Sciences Education, 13, 275-288. https://doi.org/10.1007/s10459-006-9039-x

Shi, Y. (2021). Exploring learner engagement with multiple sources of feedback on L2 writing across genres. Frontiers in Psychology, 4625. https://doi.org/10.3389/fpsyg.2021.758867.

Strijbos, J. W., Pat El, R. J., \& Narciss, S. (2021). Structural validity and invariance of the Feedback Perceptions Questionnaire. Studies in Educational Evaluation, 68. https://doi.org/10.1016/j.stueduc. 2021.100980.

Sutton, P. (2012). Conceptualizing feedback literacy: Knowing, being, and acting. Innovations in Education and Teaching International, 49(1), 31-40. https://doi.org/10.1080/14703297.2012.647781

Taber, K. S. (2018). The use of Cronbach's alpha when developing and reporting research instruments in science education. Research in Science Education, 48(6), 1273-1296. https://doi.org/10.1007/ s11165-016-9602-2

Van der Kleij, F. M. (2019). Comparison of teacher and student perceptions of formative assessment feedback practices and association with individual student characteristics. Teaching and Teacher Education, 85, 175-189. https://doi.org/10.1016/j.tate.2019.06.010

Van der Kleij, F. M., \& Lipnevich, A. A. (2020). Student perceptions of assessment feedback: A critical scoping review and call for research. Educational Assessment, Evaluation and Accountability. https://doi.org/10.1007/s11092-020-09331-x

Winstone, N \& Carless, D. (2020). Designing effective feedback processes in Higher Education. A learning focused approach. Society for Research into Higher Education Series. Routledge.

Winstone, N. E., Nash, R. A., Parker, M., \& Rowntree, J. (2017). Supporting learners' agentic engagement with feedback: A systematic review and a taxonomy of recipience processes. Educational Psychologist, 52(1), 17-37. https://doi.org/10.1080/00461520.2016.1207538

Wu, Y., \& Schunn, C. D. (2020). From feedback to revisions: Effects of feedback features and perceptions. Contemporary Educational Psychology, 60, 101826. https://doi.org/10.1016/j.cedpsych.2019. 101826

Yorke, M. (2003). Formative assessment in higher education: Moves towards theory and the enhancement of pedagogic practice. Higher Education, 45(4), 477-501. https://doi.org/10.1023/A:10239 67026413

Yu, S., Zhang, Y., Zheng, Y., Yuan, K., \& Zhang, L. (2019). Understanding student engagement with peer feedback on master's theses: A Macau study. Assessment \& Evaluation in Higher Education, 44(1), 50-65. https://doi.org/10.1080/02602938.2018.1467879

Zhang, Z. V., \& Hyland, K. (2018). Student engagement with teacher and automated feedback on L2 writing. Assessing Writing, 36, 90-102. https://doi.org/10.1016/j.asw.2018.02.004

Zhang, Z., \& Hyland, K (2022). Fostering student engagement with feedback: An integrated approach. Assessing Writing 51. https://doi.org/10.1016/j.asw.2021.100586.

Zhao, X., Cox, A., Lu, A., \& Alsuhaibani, A. (2021). A comparison of student and staff perceptions and feelings about assessment and feedback using cartoon annotation. Journal of Further and Higher Education, 1-19. https://doi.org/10.1080/0309877X.2021.1986620.

Publisher's note Springer Nature remains neutral with regard to jurisdictional claims in published maps and institutional affiliations. 


\section{Authors and Affiliations}

Rosa M. Mayordomo ${ }^{1}$ - Anna Espasa ${ }^{1} \cdot$ Teresa Guasch $^{1}$. Montserrat Martínez-Melo ${ }^{1}$

Anna Espasa

aespasa@uoc.edu

https://orcid.org/0000-0001-5520-4973

Teresa Guasch

tguaschp@uoc.edu

https://orcid.org/0000-0001-5767-1428

Montserrat Martínez-Melo

mmartinezmelo@uoc.edu

https://orcid.org/0000-0002-7015-6575

1 Department of Psychology and Education, Universitat Oberta de Catalunya (UOC), Universitat Oberta de Catalunya (UOC), Rambla del Poblenou, 156, 08018 Barcelona, Spain 